\title{
Sweat Testing and Recent Advances
}

\author{
Yasemin Gokdemir* and Bulent Taner Karadag \\ Department of Pediatric Pulmonology, Marmara University, Istanbul, Turkey
}

Cystic fibrosis (CF) is the most common fatal genetic disease of the Caucasian population. Sweat testing is the principal diagnostic test for CF, and it is used for the evaluation of infants with positive CF newborn screening (NBS) and in patients with clinical findings suggesting CF. This article describes the classical sweat test method in detail and also provides an overwiew of recent advances.

Keywords: cystic fibrosis, diagnosis, sweat test, Gibson-Cooke, chloride

\section{INTRODUCTION}

High concentrations of chloride $\left(\mathrm{Cl}^{-}\right)$detected in sweat from patients in the early 1940s resulted in the development of the sweat $\mathrm{Cl}^{-}$test (ST), and by 1959, the test was being used by Gibson and Cooke (1). Since the discovery of the cystic fibrosis (CF) gene, encoding the CF transmembrane regulator (CFTR) protein in 1989, more than 2000 mutations have been reported. The CFTR is located on the apical membrane of the epithelial cells in the exocrine secretory system that includes the sweat glands. Defective CFTR function mainly results in abnormal $\mathrm{Cl}^{-}$transport across the $\mathrm{Cl}^{-}$

\section{OPEN ACCESS}

Edited by:

Ron Rubenstein,

Washington University in St. Louis,

United States

Reviewed by:

Aleksandar Sovtic,

The Institute for Health Protection of Mother and Child Serbia, Serbia

Larry C. Lands,

McGill University, Canada

*Correspondence:

Yasemin Gokdemir yasemingokdemir@yahoo.com.tr

Specialty section:

This article was submitted to Pediatric Pulmonology,

a section of the journal

Frontiers in Pediatrics

Received: 05 January 2021

Accepted: 16 March 2021

Published: 04 May 2021

Citation:

Gokdemir Y and Karadag BT (2021) Sweat Testing and Recent Advances.

Front. Pediatr. 9:649904.

doi: 10.3389/fped.2021.649904 channels as well as diminished sodium transport across the cell membrane. Reduced $\mathrm{Cl}^{-}$secretion and enhanced sodium reabsorption across the epithelial cells increases the viscosity of secretions, and in the sweat, $\mathrm{Cl}^{-}$concentration is elevated (1-3).

Detection of elevated values of sweat $\mathrm{Cl}^{-}$by the quantitative pilocarpine iontophoresis test (QPIT) performed via chloridometer is accepted as the gold standard in CF diagnosis. This technique is performed in three stages: cholinergic stimulation of sweating with iontophoresis, collection of the sweat sample, and measurement of sweat $\mathrm{Cl}^{-}$concentration (4-9).

Well-organized and accurate ST procedures are especially important in countries with limited access to genetic testing. After the introduction of new CFTR modulators in the treatment of CF, ST has become even more important. Besides its role in the diagnosis of CF, normalization of sweat $\mathrm{Cl}^{-}$concentrations after administration of modulator therapies is used as proof of their efficacy $(10,11)$.

Because QPIT is relatively complicated to carry out; the technique and the multiple steps of the process need to be well-understood (6). Several evidence-based guidelines on how to perform the test properly have been published; each including a detailed description about sweat induction, collection, analysis, and interpretation $(4-6,8,9)$. The English language guidelines were developed by the Clinical and Laboratory Standards Institute (CLSI, USA), Multi-Disciplinary Working Group (UK), and The Australasian Association of Clinical Biochemists (AACB, Australasia) (4-6). National guidelines are also available in French and Turkish and are actively used in France and Turkey $(8,9)$.

The CLSI guideline for ST was revised in 2019 and is officially recommended by the American Cystic Fibrosis Foundation (CFF) (4). According to this guideline, there is a single agreed-upon methodology for pilocarpine iontophoresis and sweat collection but several acceptable methods for sweat analysis (7). Recent reports, however, state that there are still differences in laboratory techniques employed in testing in many countries, particularly lower income countries. Poor adherence to published guidelines suggests an inability to meet quality standards in laboratory diagnostics and, consequently, casts doubt on the accuracy of the results (10-12). 
Lack of access to pilocarpine, equipment, and trained laboratory staff, coupled with the relative difficulty of the recommended technique for QIPT have caused a search for an ST method that is easier to carry out. Additionally, collecting a sufficient amount of sweat can be challenging in infants (13, 14). For these reasons, some devices that use different, simpler methods have been developed for measuring sweat $\mathrm{Cl}^{-}$, and the safety and efficacy of these methods are reported by controlled studies (15-20). In this study, we review the QIPT and the newer alternatives now being employed in the diagnosis of CF.

\section{INDICATIONS}

The ST is indicated for individuals suspected to have CF, either from positive NBS or the presentation of clinical features suggestive of CF. CF genotyping is recommended in all patients with positive or borderline ST results and also in patients in whom ST is not technically possible. It is also necessary to identify which CF patients are eligible for CF-mutation-specific therapy. The CFF recommends CF genotyping in all patients diagnosed with $\mathrm{CF}(7,11,12,21)$.

Patients with CF may have a variety of clinical manifestations. Some neonates may have meconium ileus but have IRT levels in the normal range; in these cases, ST should be carried out. Young children may have pulmonary complications, such as recurrent pneumonia, chronic sinusitis, nasal polyps, or persistent and recurrent wheezing and coughing. The most common gastrointestinal findings are failure to thrive with malabsorptive stools and recurrent abdominal pain. Patients with these findings should be referred to the ST center (7, 21-23).

Because sweat $\mathrm{Cl}^{-}$concentration can be temporarily elevated in the first day of life, ST should be done later than $48 \mathrm{~h}$ after birth and optimally at the 10th day (4). ST should be postponed in premature infants until they reach $2 \mathrm{~kg}$ of weight and more than 36 weeks corrected gestational age. Ideally, the child should be well-hydrated and should not have acute illness. ST can be carried out for subjects requiring oxygen via mask or nasal canula. Newborns and infants that are receiving open system oxygen in the incubator should not be tested because sparks can be produced during the iontophoresis phase of the sweat test when a low electric current is applied $(4,22,23)$.

\section{SWEAT COLLECTION}

It is recommended to perform ST in an accredited care center by a trained technician (4-7). The ST is typically performed on the patient's arm or leg. The test starts with iontophoresis of pilocarpine, a parasympathomimetic alkaloid, which acts on the cholinergic receptors by mimicking acetylcholine, to stimulate sweat production by sweat glands. Collection of two simultaneous samples is recommended because of the variability of the test and insufficient sample risk (4).

In the original Gibson and Cooke method, iontophoresis is done by placing two electrodes on the patient's arm or leg and covering one of them with pilocarpine-soaked gauze and the other with deionized water-soaked gauze. An electric current of maximum $1.5 \mathrm{~mA}$ is then applied for $5 \mathrm{~min}$ to stimulate sweat production. The electrical stimulation is painless and causes no discomfort. Sweat is collected for a period of up to $30 \mathrm{~min}$. For the gauze or filter paper method, the stimulated area must be $2 \times 2$ inches. The filter paper is then placed in a laboratory dish of known weight so that the quantity of the collected sweat can be calculated. The minimum quantity required for sweat collected from the gauze method is $75 \mathrm{mg}$ (4). However, conventional procedures, such as those using gauze and filter paper, carry a significant risk of evaporation unless performed by trained and experienced staff. Errors made during sweat stimulation and collection and analysis can cause skin burns and also volumetric, gravimetric, condensate, and evaporation inaccuracies. This is especially significant in young, particularly preterm, infants $(4,13)$.

In 1983, the Wescor (Logan, Utah) Macroduct system of sweat collection was developed. This technique was easier to perform than the conventional QIPT and requires only $15 \mathrm{ml}$ of sweat. Gel discs containing pilocarpine are utilized, and the iontophoretic current passing through these discs stimulates sweat production. For safety, the iontophoretic current source needs to be battery powered. Capillary tubing is used for collecting the sweat produced by induction of sweat glands.

The sample is analyzed using a variety of techniques. In young infants, however, there is still a higher risk of insufficient quantity (QNS) ST. McColley et al. reports that $27 \%$ of CF Centers in the United States state a mean QNS rate of $10.5 \%$ in infants 14 days old or younger $(13,24,25)$. Collecting sweat from two sites is, therefore, recommended in infants. Bilateral testing increases the likelihood of collecting a sufficient specimen from at least one site. If the quantity of sweat collected from one site is insufficient for analysis, the sweat samples from various sites should not be combined; in this case, the ST should be repeated $(26,27)$.

Currently, both the Gibson and Cooke QPIT and the Macroduct ${ }^{\circledR}$ systems are recommended for sweat collection in CF diagnosis (Figures 1, 2). The Chloridometer, the conventional device for sweat $\mathrm{Cl}^{-}$analysis, also utilizes the Macroduct ${ }^{\circledR}$ coil for sweat collection (4).

In studies comparing these two systems, equivalent results are reported. The only significant difference between the Gibson and Cooke and Macroduct ${ }^{\circledR}$ QPIT sweat collection systems was sample matrix. The sample for the Gibson and Cooke QPIT is diluted because of the need for elution from the collection medium. The Macroduct ${ }^{\circledR}$ QPIT sample is collected into tubing and can be analyzed directly.

\section{BIOCHEMICAL ANALYSIS}

Coulometry is the unique method of sweat $\mathrm{Cl}^{-}$analysis approved and described in detail in the CLSI guidelines; it involves coulometric titration with a chloridometer. A chloridometer measures the free $\mathrm{Cl}^{-}$concentration in an acidic solution by allowing current to flow through a circuit. Free $\mathrm{Cl}^{-}$ions bind with silver cations generated from silver electrodes to form silver $\mathrm{Cl}^{-}$molecules; these no longer conduct the electrical current. The chloridometer measures how much current flows and how 

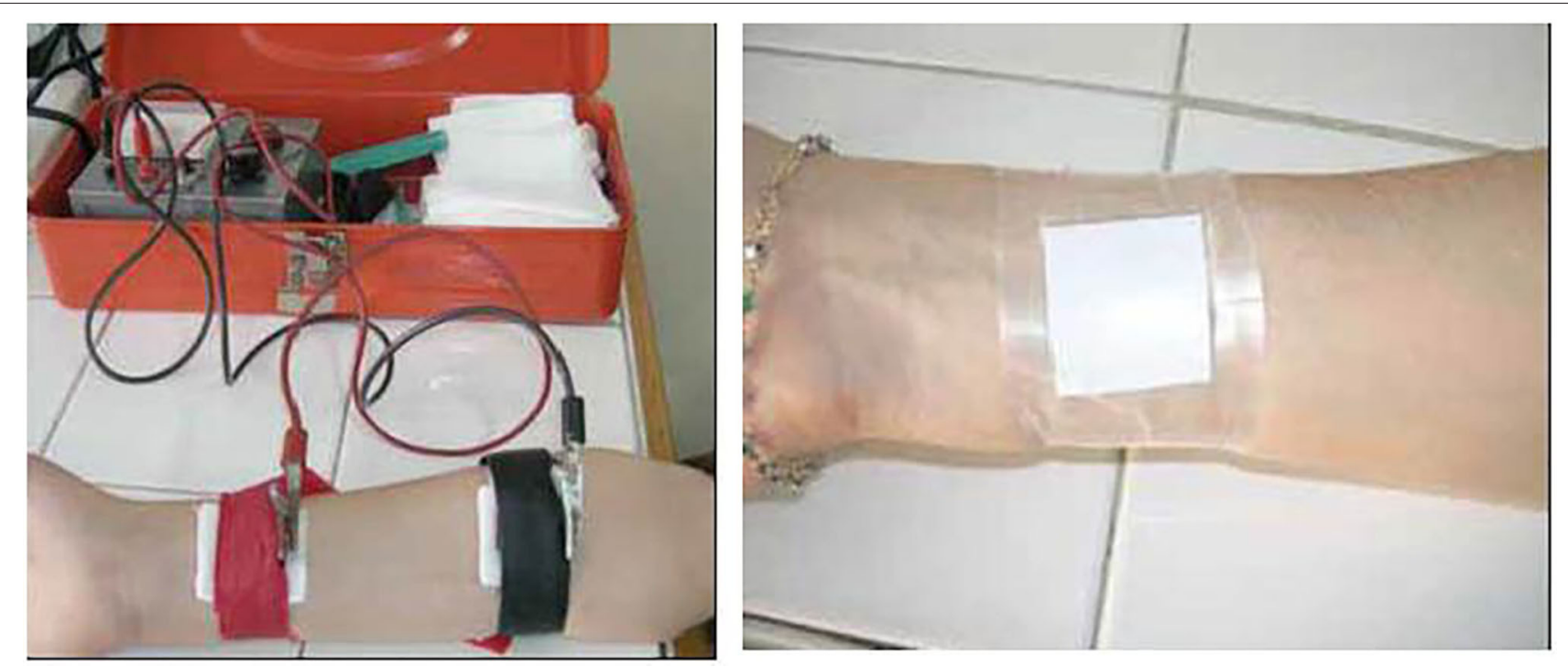

FIGURE 1 | lontopheresis and sweat collection by Gibson-Cooke method.

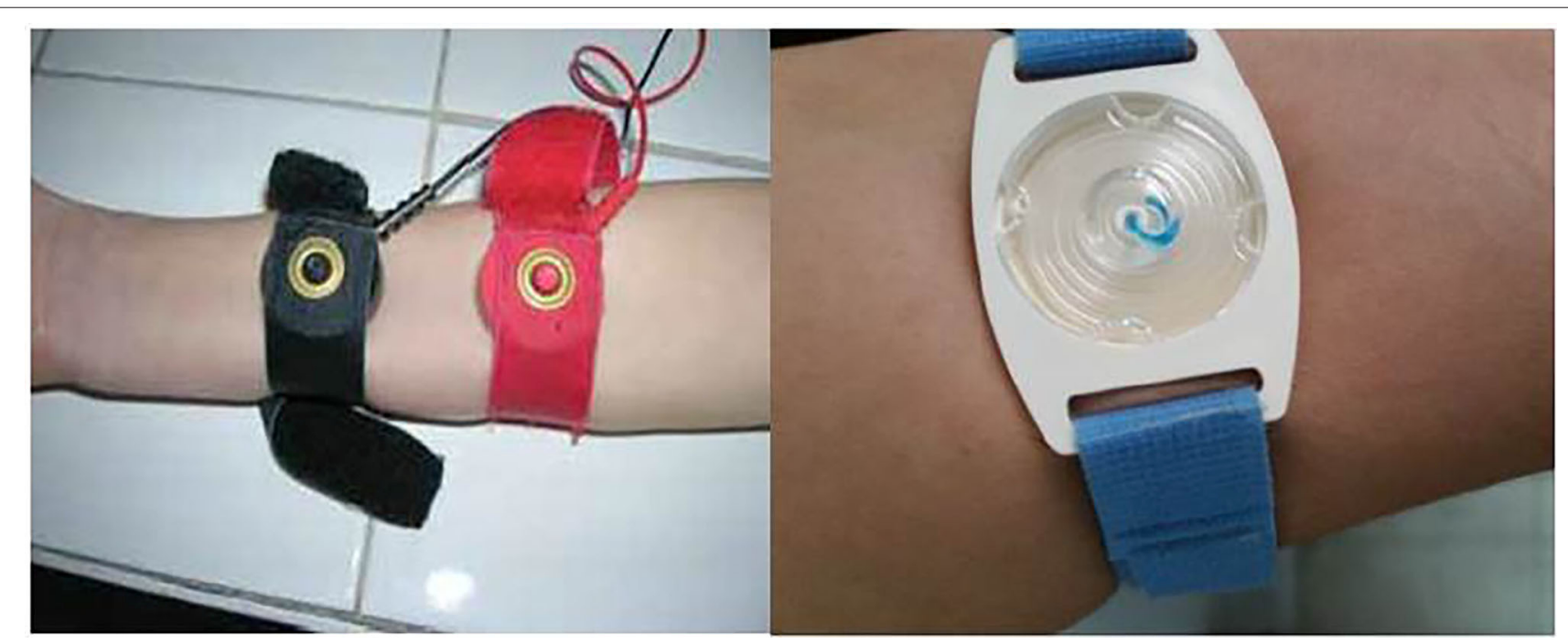

FIGURE 2 | lontopheresis and sweat collection by Macroduct System.

long it flows for in order to determine how many free $\mathrm{Cl}^{-}$ions are in the solution at the beginning of the process. Using a specimen volume of $\geq 15 \mu \mathrm{L}$, a chloridometer can measure $\mathrm{Cl}^{-}$ concentrations from 10 to $160 \mathrm{mmol} / \mathrm{L}$ (4).

Sweat collection and analysis should be performed on the same day, and the results and their interpretation should be reported to clinicians as soon as possible. Analysis of the sweat shortly after collection or within a few hours should be routine procedure for the ST center (21). Collected sweat should not be stored or transported via the coiled tubing system because of the evaporation risk. If a significant delay is expected between collection and analysis, the laboratory may store specimens in $0.2-\mathrm{mL}$ microcentrifuge tubes for $72 \mathrm{~h}$ without significant evaporation (4). For the purpose of shipment, in the case of collection of sweat during clinical trials, the specimens can be stored frozen $\left(-70^{\circ} \mathrm{C}\right)$ and accurately analyzed later.

The ion-selective electrode (ISE) method may also be used to measure $\mathrm{Cl}^{-}$, but there are limited data available on its use. This method converts the activity of a specific ion dissolved in a solution into an electrical potential, which is measured by a voltmeter (3). The ISE technique is included in the UK and Australian ST guidelines as an acceptable method; however, it has not been validated systematically for accuracy of sweat $\mathrm{Cl}^{-}$measurements. The CLSI suggests that, if it is used, the laboratory must validate the method against the traditional ST. The major concern about ISE measurement is that decreased 
sensitivity at lower concentrations could lessen the precision of the result (4-6).

\section{SWEAT $\mathrm{CL}^{-}$INTERPRETATION}

The cutoff value for sweat $\mathrm{Cl}^{-}$testing is the same regardless of a patient's age $(7,28)$. A level of $\mathrm{Cl}^{-}$of higher than 60 $\mathrm{mmol} / \mathrm{L}$ in the sweat is indicative of CF; concentrations lower than $30 \mathrm{mmol} / \mathrm{L}$ are considered normal, and CF is unlikely. A level between 30 and $59 \mathrm{mmol} / \mathrm{L}$ is defined as intermediate (borderline), and repeated ST or additional diagnostic tests are required (28). After a positive ST result, either ST is repeated or genetic testing is performed to confirm the definite CF diagnosis (12). A diagnostic algorithm for CF for interpreting the results of the ST is presented in Figure 3.

\section{INTERFERING FACTORS}

Variability in sweat $\mathrm{Cl}^{-}$levels is shown in previous studies, but sweat $\mathrm{Cl}^{-}$biological variability, in both healthy people and $\mathrm{CF}$ patients is not well-known $(29,30)$. Results from a total of 5,960 tests from two CF centers were reported by Vermeulen et al. According to this study, in $90 \%$ of subjects, -3.2 and +3.6 $\mathrm{mmol} / \mathrm{L}$ changes were obtained from samples taken on both sides collected at the same test occasion. However, two separate tests showed much higher variability with changes between -18 and $+14 \mathrm{mmol} / \mathrm{L}$ in $90 \%$ of the subjects. Biological variability mostly affected the intermediate test results, and some of them returned to within normal range with the repeated tests in that study. On the other hand, sweat $\mathrm{Cl}^{-}$values higher than $60 \mathrm{mmol} / \mathrm{L}$ showed small biological variability (30).

Another concern regarding ST is false positive cases. The most common reason for a false positive ST is technical error during the procedure, such as evaporation of the sweat sample. The incidence of this problem is reduced by correct implementation and adherence to recommended testing procedures and by ensuring that the test is performed in adequately equipped laboratories and by properly trained personnel (4).

Sweat $\mathrm{Cl}^{-}$levels may also be elevated falsely in other pathologic conditions, including atopic dermatitis, ectodermal dysplasia, pseudohypoaldosteronism, untreated hypothyroidism, glycogen storage disease type I, carbonic anhydrase XII mutations, malnutrition, and anorexia nervosa. Elevated sweat $\mathrm{Cl}^{-}$concentrations in non-CF patients may also be related to iatrogenic causes, such as mineralocorticoid, $\mathrm{NaCl}^{-}$perfusion, and topiramate treatment (21). The underlying mechanism for false positive results in many conditions is unknown. The possible sweat gland function impairment associated with the skin manifestations may be the reason for high levels of sweat $\mathrm{Cl}^{-}$in patients with atopic dermatitis and ectodermal dysplasia (31). Hyperchlorhidrosis caused by otosomal recessive inherited Carbonic Anhydrase XII deficiency should be considered in the differential diagnosis of a positive ST, especially with the clinical findings of hyponatremic dehydration during infancy. High sweat $\mathrm{Cl}^{-}$levels during treatment with topiramate may be the result of the inhibition of carbonic anhydrase isotypes in the sweat gland ducts (32).

\section{REPORTING RESULTS}

Name, surname, and the date of birth of the patient and the date and hour of the test should be recorded. The type of ST employed; the level of $\mathrm{Cl}^{-}$measured; the unit of measurement; if the value is normal, borderline, or high; and the interpretation of the test result should all be specified in the test report. $\mathrm{Cl}^{-}$concentrations in whole numbers should be reported using mmol/L units. In quantitative $\mathrm{Cl}^{-}$measurements, $\mathrm{mmol} / \mathrm{L}$ and milliequivalent per liter $(\mathrm{mEq} / \mathrm{L})$ are equivalent. It is not necessary to report the total sweat volume collected if an adequate volume was ensured (4).

\section{OTHER ST METHODS}

\section{Conductivity}

Although quantitative sweat $\mathrm{Cl}^{-}$measurement is the unique approved method for CF diagnosis, sweat conductivity measurement is easier and also commonly used in many settings throughout the world. Conductivity depends on the concentration and mobility of the ions within a solution and reflects a non-selective measurement of ions. As the bicarbonate and lactate ions in the sweat affect the conductivity, results do not show the sweat $\mathrm{Cl}^{-}$concentration $(26,27,33)$. Mean sweat conductivity test results are $\sim 15-20 \mathrm{mmol} / \mathrm{L}$ higher than sweat $\mathrm{Cl}^{-}$measurement. Several sweat conductivity measuring instruments are available.

A conductivity instrument was approved as a screening method (8). A sweat conductivity test result is defined as abnormal if the value is $\geq 50 \mathrm{mmol} / \mathrm{L}$, and these patients should be referred for a quantitative ST to confirm the diagnosis of CF (4).

According to the CLSI guideline, conductivity should not be used as a diagnostic test for infants with a positive NBS result. These babies should be tested with quantitative ST (4). There are many studies, however, that have compared the conductivity ST method with conventional coulometric ST and that show adequate efficacy and safety $(15,33,34)$.

Nanoduct ${ }^{\circledR}$ is one of the ST devices used with the conductivity method. It was developed especially for use with newborns, and only $3 \mu \mathrm{L}$ of sweat is required. As soon as sweat enters the microconductivity cell, the ST result is shown on the display (35).

In the national NBS program for CF in Switzerland, Macroduct ${ }^{\circledR}$ collection (with $\mathrm{Cl}^{-}$concentration measurement) and Nanoduct ${ }^{\circledR}$ test (measuring conductivity) methods were compared. Although only $60 \%$ of Macroduct ${ }^{\circledR}$ tests were successful at the first attempt, the Nanoduct $($ had a higher rate of successful outcome (79\%), and it was as sensitive as the Macroduct ${ }^{\circledR}$ in identifying newborns with CF (sensitivity 98 vs. 99\%, respectively) but less specific (specificity 79 vs. 93\%) (35). Another study from the Netherlands also showed that Nanoduct ${ }^{\circledR}$ fails less often in newborns than the Gibson and Cooke/Macroduct ${ }^{\circledR}$ because it can operate with a small quantity of sweat, and it is, therefore, advocated that it can be used to 


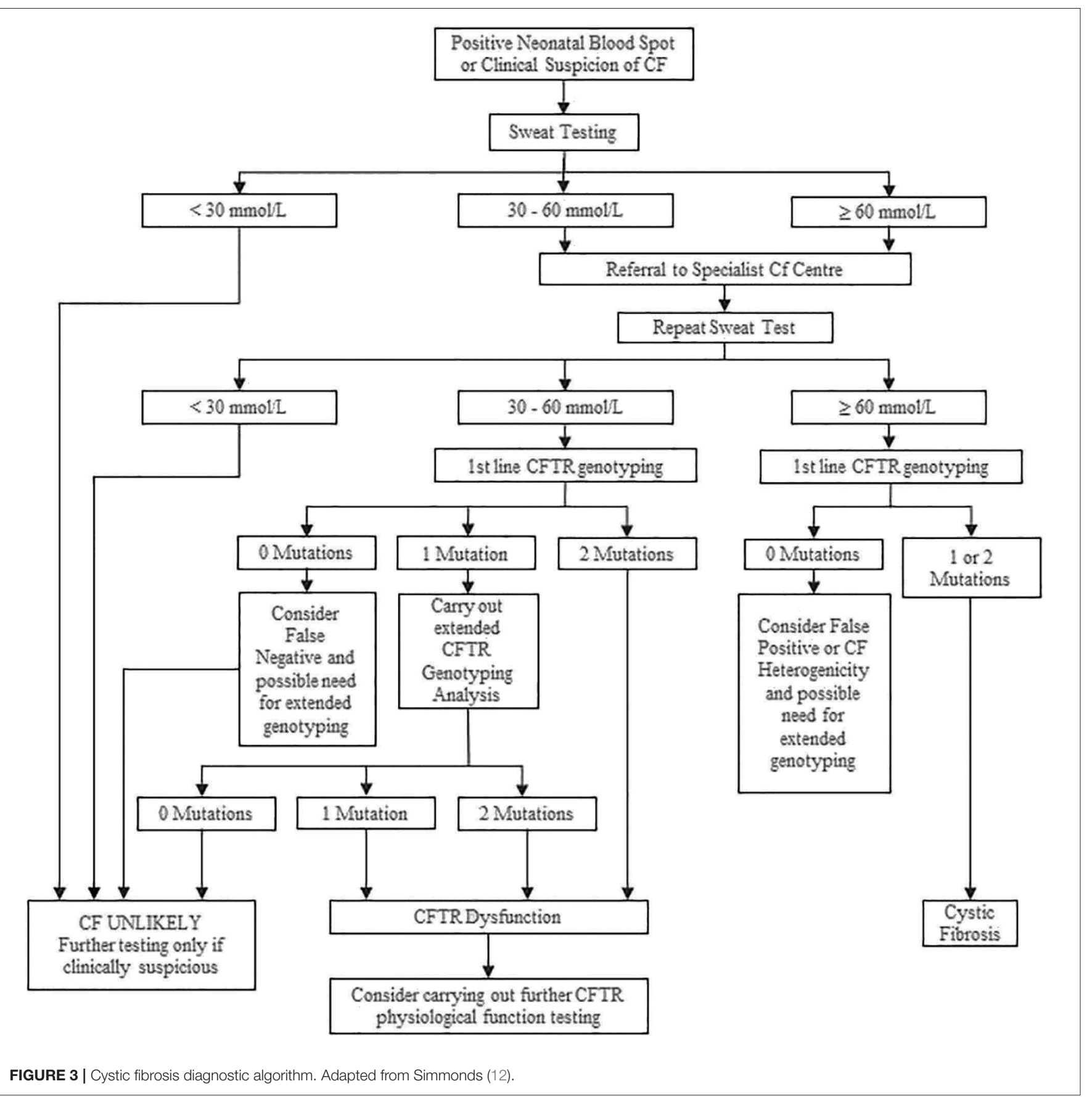

confirm the diagnosis CF in infants with a positive NBS test for CF (36).

\section{Coulometric Endpoint Method}

The coulometric endpoint method utilizes an electrolysis reaction measuring the changes in resistance to the current flowing between electrodes. The concentration of the solution is equivalent to the current generated. Sweat is collected by a tube similar to Macroduct ${ }^{\circledR}$ coil that reduces the risk of sample evaporation. This method is approved by the CLSI, UK, and Australian ST guidelines (4-6).
The CF $\Delta$ Collection System ${ }^{\circledR}$ is a new-generation, ST analyzer manufactured by UTSAT, which is based on this coulometric end point method. Studies comparing this device with quantitative sweat $\mathrm{Cl}^{-}$analysis demonstrate that the coulometric end point method is safe and can be as reliable as gold standard methods. This device is approved by CE, commercially available, and routinely used in Turkey, in some of the Middle East and African countries, and in Azerbaijan $(18,37)$.

This method was compared with both the titrimetric $\mathrm{Cl}^{-}$ measurement (Sherwood $\AA$ ) Chloridometer 926S, Sherwood Scientific Ltd., Cambridge, UK) and the classical Gibson and 
Cooke and manual titration methods. Bland-Altman plots were used to analyze the agreement between methods in the healthy controls and the CF subjects. Good agreement was obtained between the coulometric end point technique and the gold standart ST methods (18).

\section{Ion Exchange Technology: Wearable Sweat Sensor}

This technique is based on ion exchange technology accepted by the CLSI Guidelines and measures quantitative Cl- levels with the accuracy of the traditional method (19).

Recently, several reports have been published on wearable sweat $\mathrm{Cl}$ analyzer for CF diagnosis $(16,19)$. CF Quantum ${ }^{\circledR}$ Sweat Test System (CFQT) is one example that is awaiting approval by the FDA and the CE; it is manufactured by Medtronic Inc., Minneapolis, Minnesota. Sweat production is stimulated with pilocarpine via a portable, wearable electrode and collected by a $\mathrm{Cl}^{-}$test patch. Finally, the sweat $\mathrm{Cl}^{-}$value is calculated by an analyzer after scanning the patch with a camera. The time needed to achieve a reliable result is short, and the result is reported in $30 \mathrm{~min}$ with a small sample volume $(9 \mu \mathrm{L})$. This technique was compared with the conventional coulometric method in both CF patients and healthy controls. The sweat $\mathrm{Cl}^{-}$concentrations obtained from the wearable sensor showed excellent agreement with the conventional tests with a Pearson correlation coefficient of $p=0.97$. Sweat $\mathrm{Cl}^{-}$measurements for all healthy subjects were within the accepted threshold for normal ( $\leq 29 \mathrm{mEq} / \mathrm{L} ; 16-27)$, and all individuals with CF were above the accepted threshold ( $\geq 60 \mathrm{mEq} / \mathrm{L} ; 65-130$ ), confirming CF diagnosis. The correlation coefficient between the CFQT and conventional ST was 0.98 [95\% confidence interval (CI): 0.970.99]. The sensitivity and specificity of the CFQT in diagnosing CF was $100 \%$ (95\% CI: $94-100 \%$ ) and 96\% (95\% CI: $89-99 \%)$, respectively (16).

\section{Inductively Coupled Plasma Mass Spectrometry (ICP-MS)}

ICP-MS is used in the clinical laboratory on a routine basis to an increasing extent, mainly to determine the presence of oligoelements. It can also be employed for sweat $\mathrm{Cl}^{-}$assay and provides accurate measurements, especially at low $\mathrm{Cl}^{-}$ concentrations (38). Pullan et al. used ICP-MS to analyze sweat $\mathrm{Cl}^{-}$and sodium for the measurement of ST, collected via a Macroduct ${ }^{\circledR}$ sweat collector tube (39). Collie et al. demonstrated that both online (instrument based) and off-line (sample based) internal standard methods measuring $\mathrm{Cl}$ - were successful in providing accurate, reproducible results (17). Marvelli et al. conducted a study comparing this method with gold standard coulometric titration in 50 healthy volunteers and two CF patients. The method was then cross-validated by assaying 50 standard samples with $\mathrm{Cl}^{-}$concentration values in the range $10-131 \mathrm{mM}$ by both ICP-MS and coulometric titration. BlandAltman plots confirmed the analogous concentration levels for coulometric titration and ICP-MS; bias had a value of -0.9 $(95 \%$ CI $=-1.96 \div 0.20)$ with lower and upper limits of agreement of $-8.3(95 \% \mathrm{CI}=-10.18 \div-6.47)$ and $6.6(95 \%$ $\mathrm{CI}=4.71 \div 8.42)$, respectively. Consequently, the authors report good correlation between the two $\mathrm{Cl}^{-}$analysis techniques
(38). Although not involved in any of the current English language ST guidelines, ICP-MS is utilized by a number of ST laboratories, especially in Australia, the UK, and Italy. Authors confirm this method is as safe and accurate as the conventional coulometric method and suggest it be recognized as a candidate reference method for the monitoring and diagnosis of CF $(17,39,40)$.

\section{Capillary Electrophoresis: Skin Wipe Test (SWT)}

In the SWT, unstimulated, spontaneously formed sweat is collected using a cotton swab moistened with deionized water, then extracted. The collection procedure is non-invasive and faster than the conventional ST method. Evaluation by SWT with contactless conductivity detection, typically performed in the biochemical laboratory, analyzes the whole "sweat ionome" (41).

Durc et al. compared SWT with the conventional coulometric method in 114 CF patients, 76 healthy carriers, and 58 controls. The SWT method with capillary electrophoretic analysis for CF diagnosis performed comparably with the conventional Macroduct ${ }^{\circledR}$ ST. The SWT method evaluated $\mathrm{Cl}^{-} / \mathrm{K}^{+}$and $\left(\mathrm{Cl}^{-}+\mathrm{Na}^{+}\right) / \mathrm{K}^{+}$ion ratios for $\mathrm{CF}$ diagnosis. Two ion ratios, $\mathrm{Cl}^{-} / \mathrm{K}^{+}$and $\left(\mathrm{Cl}^{-}+\mathrm{Na}^{+}\right) / \mathrm{K}^{+}$, from the SWT samples and $\mathrm{Cl}^{-}$ values from the ST samples were evaluated to diagnose $\mathrm{CF}$. Sensitivity of the SWT method using the $\mathrm{Cl}^{-} / \mathrm{K}^{+}$ratio (cutoff value 3.9) was $93.9 \%$ compared with $99.1 \%$ when using the $\left(\mathrm{Cl}^{-}+\mathrm{Na}^{+}\right) / \mathrm{K}^{+}$ratio (cutoff value 5.0$)$ and $98.3 \%$ in using Macroduct $\mathrm{Cl}^{-}$(cutoff value higher or equal to $60 \mathrm{mmol} / \mathrm{L}$ ). The method specificities were 97.8, 94.0, and $100.0 \%$, respectively. The authors propose the SWT as a new diagnostic technique for CF (20).

\section{ST for Outcomes in Clinical Trials}

The increased use of CFTR modulators in the treatment of CF has highlighted the need for precise and accurate biomarkers to evaluate their efficacy. These therapies may not result in equivalent clinical improvement for all CFTR mutations, and the $\mathrm{Cl}^{-}$concentration in sweat can serve as a useful biomarker of CFTR function, in vivo, in assessing the response to modulator treatments (18). In terms of the treatment response, studies show correlations between functional classes of CFTR variants and sweat $\mathrm{Cl}^{-}$concentration $(19,20)$. In clinical use, baseline and serial sweat $\mathrm{Cl}^{-}$measurements are usually used to monitor the effects of therapies targeting CFTR function in previously diagnosed CF patients $(4,16,17,21)$.

\section{CONCLUSION}

Sweat $\mathrm{Cl}^{-}$concentration is the first-choice test to confirm a CF diagnosis. In addition to this, it is also essential in monitoring the efficacy of modulator treatments. All steps of ST are subject to a risk of error, resulting from inexperienced laboratory personnel or lack of appropriate quality assurance. Inaccurate methodology of the sweat collection, technical error, and misinterpretation of the results are all possible. Additionally, with the increasing frequency of NBS all over the world, the need for ST in the neonatal period and also in very low-weight babies is increasing. 
These have all led to efforts to create easier to carry out but still reliable, ST methods and procedures. Although, as described in the paper, a number of newer methods have been developed and are being used, these methods still need careful interpretation in decision making for $\mathrm{CF}$.

\section{REFERENCES}

1. Gibson LE, Cooke RE. A test for concentration of electrolytes in sweat in cystic fibrosis of the pancreas utilizing pilocarpine by iontophoresis. Pediatrics. (1959) 23:545-9.

2. Warwick WJ, Viela I, Hansen LG. Comparison of the errors due to the use of gauze and the use of filter paper in the gravimetric chloride titration sweat test. Am J Clin Pathol. (1979) 72:211-5. doi: 10.1093/ajcp/72.2.211

3. Collie JT, Massie RJ, Jones OA, LeGrys VA, Greaves RF. Sixty-five years since the New York heat wave: advances in sweat testing for cystic fibrosis. Pediatr Pulmonol. (2014) 49:106-17. doi: 10.1002/ppul.22945

4. CLSI. Sweat testing: specimen collection and quantitative chloride analysis. CLSI Guideline C34. 4th ed. Wayne, PA: Clinical and Laboratory Standards Institute (2019).

5. Massie J, Greaves R, Metz M, Wiley V, Graham P, Shepherd S, et al. Australasian guideline (2nd Edition): an annex to the CLSI and UK Guidelines for the performance of the sweat test for the diagnosis of cystic fibrosis. Clin Biochem Rev. (2017) 38:115-30.

6. Multi Disciplinary Working Group. Guidelines for the Performance of the Sweat Test for the Investigation of Cystic Fibrosis in the UK. 2nd ed. Birmingham: Multi Disciplinary Working Group (2014).

7. Farrell PM, Rosenstein BJ, White TB, Accurso FJ, Castellani C, Cutting GR, et al. Cystic fibrosis foundation. Guidelines for diagnosis of cystic fibrosis in newborns through older adults: cystic Fibrosis Foundation consensus report. J Pediatr. (2008) 153:S4-14. doi: 10.1016/j.jpeds.2008.05.005

8. Sermet-Gaudelus I, Munck A, Rota M, Roussey M, Feldmann D. Recommandations Franc,aises pour la R_ealisation et l'Interpr_etation du Test de la Sueur dans le Cadre du D_epistage N_eonatal de la Mucoviscidose. Arch Fr Pediatr. (2010) 17:1349-58. doi: 10.1016/j.arcped.2010.06.021

9. Özçelik U, Karakoç F, Yüksel H, Yilmaz Ö, Gürcan N. Ulusal yenidogan tarama programi kistik fibrozis taramasi, Ter testi rehberi. Ankara. T.C. Saglik Bakanligi Türkiye Halk Sagligi Kurumu (2015).

10. Kabir AL, Roy S, Habib RB, Anwar KZ, Mollah AS, Amin R, et al. Cystic fibrosis diagnosed using indigenously wrapped sweating technique: first large-scale study reporting socio-demographic, clinical, and laboratory features among the children in Bangladesh a lower middle income country. Glob Pediatr Health. (2020) 30:7:2333794X20967585. doi: 10.1177/2333794X20967585

11. Bienvenu T, Nguyen-Khoa T. Current and future diagnosis of cystic fibrosis: performance and limitations. Arch Pediatr. (2020) 27:eS1924. doi: 10.1016/S0929-693X(20)30046-4

12. Simmonds NJ. Is it cystic fibrosis? The challenges of diagnosing cystic fibrosis. Paediatr Respir Rev. (2019) 31:6-8. doi: 10.1016/j.prrv.2019.02.004

13. McColley SA, Elbert A, Wu R, Ren CL, Sontag MS, LeGrys VA. Quantity not sufficient rates and delays in sweat testing in US infants with cystic fibrosis. Pediatr Pulmonol. (2020) 55:3053-56. doi: 10.1002/ppul.25027

14. LeGrys VA, Moon TC, Laux J, Accurso F, Martiniano SA. Multicenter evaluation of sweat chloride concentration and variation in infants with cystic fibrosis. J Cyst Fibros. (2019) 18:190-3. doi: 10.1016/j.jcf.2018.12.006

15. Cinel G, Dogru D, Yalçin E, Özçelik U, Gürcan N, Kiper N. Sweat conductivity test: can it replace chloride titration for cystic fibrosis diagnosis? Turk J Pediatr. (2012) 54:576-82.

16. Rock MJ, Makholm L, Eickhoff J. A new method of sweat testing: the cf quantum $\AA$ sweat test. J Cyst Fibros. (2014) 13:520-7. doi: 10.1016/j.jcf.2014.05.001

17. Collie JT, Massie RJ, Jones OAH, Morrison PD, Greaves RF. A candidate reference method using ICP-MS for sweat chloride quantification. Clin Chem Lab Med. (2016) 54:561-7. doi: 10.1515/cclm-2015-0506

\section{AUTHOR CONTRIBUTIONS}

YG and BK have made contributions to the design, editing, and writing of this manuscript. All authors contributed to the article and approved the submitted version.

18. Gokdemir Y, Vatansever P, Karadag B, Seyrekel T, Baykan O, Ikizoglu NB, et al. Performance evaluation of a new coulometric endpoint method in sweat testing and its comparison with classic Gibson\&Cooke and chloridometer methods in cystic fibrosis. Front Pediatr. (2018) 6:133. doi: 10.3389/fped.2018.00133

19. Choi DH, Thaxton A, Jeong I, Kim K, Sosnay PR, Cutting GR, et al. Sweat test for cystic fibrosis: Wearable sweat sensor vs. standard laboratory test. J Cyst Fibros. (2018) 17:e35-e38. doi: 10.1016/j.jcf.2018.03.005

20. Durč P, Foret F, Homola L, Malá M, Pokojová E, Vinohradská H, et al. Skin wipe test: a simple, inexpensive, and fast approach in the diagnosis of cystic fibrosis. Pediatr Pulmonol. (2020) 55:1653-60. doi: 10.1002/ppul.24758

21. Dayasiri K, Hull J, Rao S. NICE guidance on diagnosis and management of cystic fibrosis. Arch Dis Child Educ Pract Ed. (2021) 106:31-4. doi: 10.1136/archdischild-2019-316882

22. Massie J, Gaskin K, Asperen PV, Wilcken B. Sweat testing following newborn screening for cystic fibrosis. Pediatr Pulmonol. (2000) 29:452-6. doi: 10.1002/ (SICI)1099-0496(200006)29:6<452::AID-PPUL7>3.0.CO;2-H

23. Castellani C, Duff AJA, Bell SC, Heijerman HGM, Munck A, Ratjen F, et al. ECFS best practice guidelines: the 2018 revision. J Cyst Fibros. (2018) 17:153-78. doi: 10.1016/j.jcf.2018.02.006

24. Webster HL. Laboratory diagnosis of cystic fibrosis. Crit Rev Cl Lab Sci. (1983) 23:545-9.

25. Wescor Inc. Available online at: http://www.wescor.com/biomedical/ cysticfibrosis/macroduct.html (accessed April 17, 2021).

26. Hammond KB, Turcios NL, Giboson LE. Clinical evaluation of the macroduct sweat collection system and conductivity analyzer in the diagnosis of cystic fibrosis. J Pediatr. (1994) 124:255-60. doi: 10.1016/S0022-3476(94)70314-0

27. Mastella G, Di Cesare G, Borruso A, Menin L, Zanolla L. Reliability of sweattesting by the macroduct collection method combined with conductivity analysis in comparison with the classic gibson and cook technique. Acta Paediatr. (2000) 89:933-7. doi: 10.1080/080352500750043378

28. Brown A, Jenkins L, Reid A, Leavy, McDowell G, McIlroy C, et al. How to perform and interpret the sweat test? Arch Dis Child Educ Pract Ed. (2020) 105:230-35. doi: 10.1136/archdischild-2018-316615

29. Vermeulen F, Lebecque P, De Boeck K, Leal T. Biological variability of the sweat chloride in diagnostic sweat tests: a retrospective analysis. J Cyst Fibros. (2017) 16:30-5. doi: 10.1016/j.jcf.2016.11.008

30. LeGrys VA, Moon TC, Laux J, Rock MJ, Accurso M. Analytical and biological variation in repeated sweat chloride concentrations in clinical trials for CFTR modulator therapy. J Cyst Fibros. (2018) 17:43-9. doi: 10.1016/j.jcf.2017.07.008

31. Guglani L, Stabel D, Weiner DJ. False-positive and false-negative sweat tests: systematic review of the evidence. Pediatr Allergy Immunol Pulmonol. (2015) 8:198-211. doi: 10.1089/ped.2015.0552

32. Guglani L, Sitwat B, Lower D, Kurland G, Weiner DJ. Elevated sweat chloride concentration in children without cystic fibrosis who are receiving topiramate therapy. Pediatr Pulmonol. (2012) 47:429-33. doi: 10.1002/ppul.21563

33. Mattar AC, Gomes EN, Adde FV, Leone C, Mattar AC, Gomes EN, et al. Comparison between classic gibson and cooke technique and sweat conductivity test in patients with and without cystic fibrosis. J Pediatr. (2010) 86:109-14. doi: 10.2223/JPED.1979

34. Lezana JL, Vargas MH, Karam-Bechara J, Aldana RS, Furuya ME. Sweat conductivity and chloride titration for cystic fibrosis diagnosis in 3834 subjects. J Cyst Fibros. (2003) 2:1-7. doi: 10.1016/S1569-1993(02)00146-7

35. Rueegg CS, Kuehni CE, Gallati S, Jurca M, Jung A, Casaulta C, et al. Swiss Cystic Fibrosis Screening Group. Comparison of two sweat test systems for the diagnosis of cystic fibrosis in newborns. Pediatr Pulmonol. (2019) 54:264-72. doi: 10.1002/ppul.24227 
36. van Langen AV, Dompeling E, Yntema JB, Arets B, Tiddens H, Loeber G. Jeannette clinical evaluation of the nanoduct sweat test system in the diagnosis of cystic fibrosis after newborn screening. Eur J Pediatr. (2015) 174:1025-34. doi: 10.1007/s00431-015-2501-0

37. Emiralioglu N, Özçelik U, Yalçin E, Dogru D, Kiper N. Diagnosis of cystic fibrosis with chloride meter (Sherwood M926S chloride analyzer) and sweat test analysis system (CFdelta collection system) compared to the Gibson Cooke method. Turk J Pediatr. (2016) 58:27-33. doi: 10.24953/turkjped.2016.01.004

38. RCPA Quality Assurance Programs. Sweat Electrolyte End of Cycle 27 Report. Available online at: www.rcpaqap.com.au/chempath (accessed November 10, 2013).

39. Pullan NJ, Thurston V, Barber S. Evaluation of an inductively coupled plasma mass spectrometry method for the analysis of sweat chloride and sodium for use in the diagnosis of cystic fibrosis. Ann Clin Biochem. (2013) 50 (Pt 3):267-70. doi: 10.1177/0004563212474565

40. Marvelli A, Campi B, Mergni G, Di Cicco ME, Turini P, Scardina P. Sweat chloride assay by inductively coupled plasma mass spectrometry: a confirmation test for cystic fibrosis diagnosis. Anal Bioanal Chem. (2020) 412:6909-16. doi: 10.1007/s00216-020-02821-3

41. Kubán P, Greguš M, Pokojová E, Skričková J, Foret F. Double opposite end injection capillary electrophoresis with contactless conductometric detection for simultaneous determination of chloride, sodium and potassium in cystic fibrosis diagnosis. J Chromatogr A. (2014) 1358:293-8. doi: 10.1016/j.chroma.2014.06.091

Conflict of Interest: The authors declare that the research was conducted in the absence of any commercial or financial relationships that could be construed as a potential conflict of interest.

Copyright (C) 2021 Gokdemir and Karadag. This is an open-access article distributed under the terms of the Creative Commons Attribution License (CC BY). The use, distribution or reproduction in other forums is permitted, provided the original author(s) and the copyright owner(s) are credited and that the original publication in this journal is cited, in accordance with accepted academic practice. No use, distribution or reproduction is permitted which does not comply with these terms. 